\title{
Synthesis and Second-Order Nonlinear Optical Properties of Tricyanovinylated Polybenzoxazole
}

\author{
Ki Hong Park, Sangyup Song, Yong Seok LeE, \\ Chul Joo LEE, and Nakjoong $\mathrm{KIM}^{\dagger}$ \\ Division of Polymer Research, Korea Institute of Science and Technology, \\ P.O. Box 131, Cheongryang, Seoul 130-650, Korea
}

(Received September 30, 1997)

\begin{abstract}
We have developed the second-order nonlinear optically (NLO) active polybenzoxazole as a new thermally stable NLO polymeric system. This polybenzoxazole was synthesized by direct polycondensation of diacid monomer containing $N$-phenyl pendant with 2,2-bis(3-amino-4-hydroxyphenyl)-1,1,1,3,3,3-hexafluoropropane using phosphorus pentoxide/methanesulfonic acid as a condensing agent and solvent, followed by a post-substitution of tricyanovinyl group. The resultant polybenzoxazole had a glass transition temperature of about $180^{\circ} \mathrm{C}$ and an initial decomposition temperature of about $300^{\circ} \mathrm{C}$. Electro-optic coefficient of this polybenzoxazole film poled at $1.5 \mathrm{MV} \mathrm{cm}^{-1}$ was $34 \mathrm{pm} \mathrm{V}^{-1}$ (at $633 \mathrm{~nm}$ ), and its $\mathrm{NLO}$ activity was quite stable at $100^{\circ} \mathrm{C}$ during long period.

KEY WORDS Polybenzoxazole / Nonlinear Optics / Tricyanovinyl / Thermal Stability / Electro-Optic Coefficient /
\end{abstract}

For photonic devices such as electro-optic modulator or optical switch, polymeric second-order nonlinear optical (NLO) materials might be a promising candidate for low cost devices and their mass productions due to their excellent processability compared to general lithium niobate crystals. ${ }^{1-3}$ Large electro-optic coefficient $\left(r_{33}\right)$, its long-term temporal stability, low optical loss, and good photostability of polymeric NLO materials are required for the practical photonic applications. One of the most critical problems in polymeric systems is the gradual decay of NLO activity during prolonged period. Recently, several successful polyimides systems have been reported for temporally stable photonic devices, which had high glass transition temperatures and decomposition temperatures. ${ }^{4-8}$ We have recently found that polybenzoxazole might also be one of the good candidates for thermally stable NLO materials comparable to polyimide.

In our previous study, we have successfully synthesized several novel NLO chromophores having a benzoxazole $\pi$-conjugated bridge, which are more thermally stable and highly NLO active than conventional stilbene type chromophores. ${ }^{9}$ The main-chain benzoxazole polymer was chosen for the same reason as the side-chain benzoxazole chromophore of polymethylmethacrylate copolymer (Figure 1). Fully aromatic polybenzoxazole was known to have excellent thermal and oxidative stability comparable to polyimides. ${ }^{10}$ Moreover, it is expected that polybenzoxazoles could have lower moisture absorption than polyimides because polybenzoxazoles have no carbonyl groups in their structure, providing for more reliable materials for photonic devices.

In this study, we report the synthesis, thermal and nonlinear optical properties of polybenzoxazole.

\section{EXPERIMENTAL}

\section{Materials}

4-Fluorobenzonitrile and $\mathrm{N}$-phenyldiethanolamine were used as received from Aldrich Chemical Co. 2,2Bis(3-amino-4-hydroxyphenyl)-1,1,1,3,3,3-hexafluoropropane (6FAP) was supplied by Central Glass Co., Japan as white powder; $\mathrm{mp} 243-245^{\circ} \mathrm{C}$. Phosphorus pentoxide/methanesulfonic acid (PPMA) was obtained commercially from Tokyo Chemical Industry Co.

\section{Characterization and Measurement}

FT-IR, UV-Vis, and ${ }^{1} \mathrm{H}$ NMR spectra were recorded on a Mattson Alpha Centauri spectrophotometer, a Shimadzu UV-240, and a Varian Gemini 200 NMR spectrometer $(200 \mathrm{MHz})$, respectively. Differential scanning calorimeter (DSC) and thermogravimetry (TG) were performed with Dupont thermal analyzer. Electro-optic coefficient was measured by the modified simple reflection method proposed by Teng et al., and the film processing, poling, and electro-optic measurement procedure was reported by our recent literature in detail. ${ }^{11}$

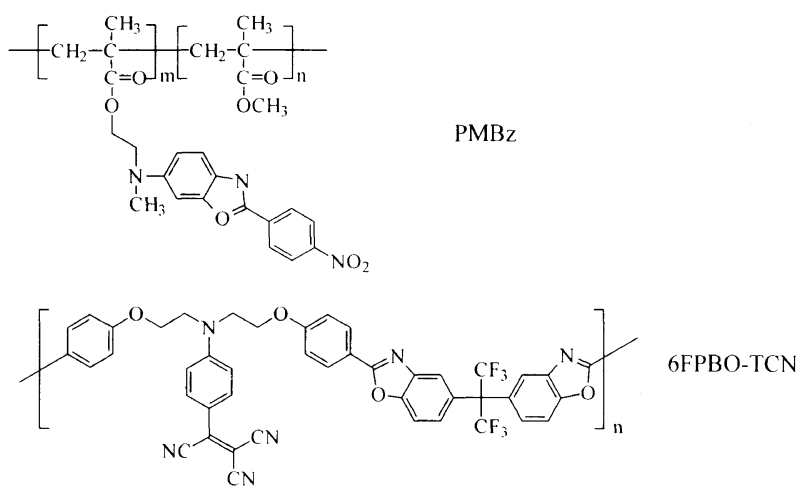

Figure 1. NLO active PMMA copolymer (PMBz) containing benzoxazole chromophores and polybenzoxazole (6FPBO-TCN). 
<smiles>OCCN(CCCl)c1ccccc1</smiles>

1

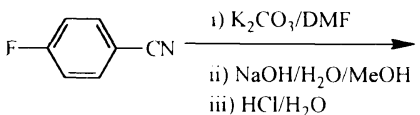

2<smiles>O=C(O)c1ccc(OCCN(CCOc2ccc(C(=O)O)cc2)c2ccccc2)cc1</smiles>

4

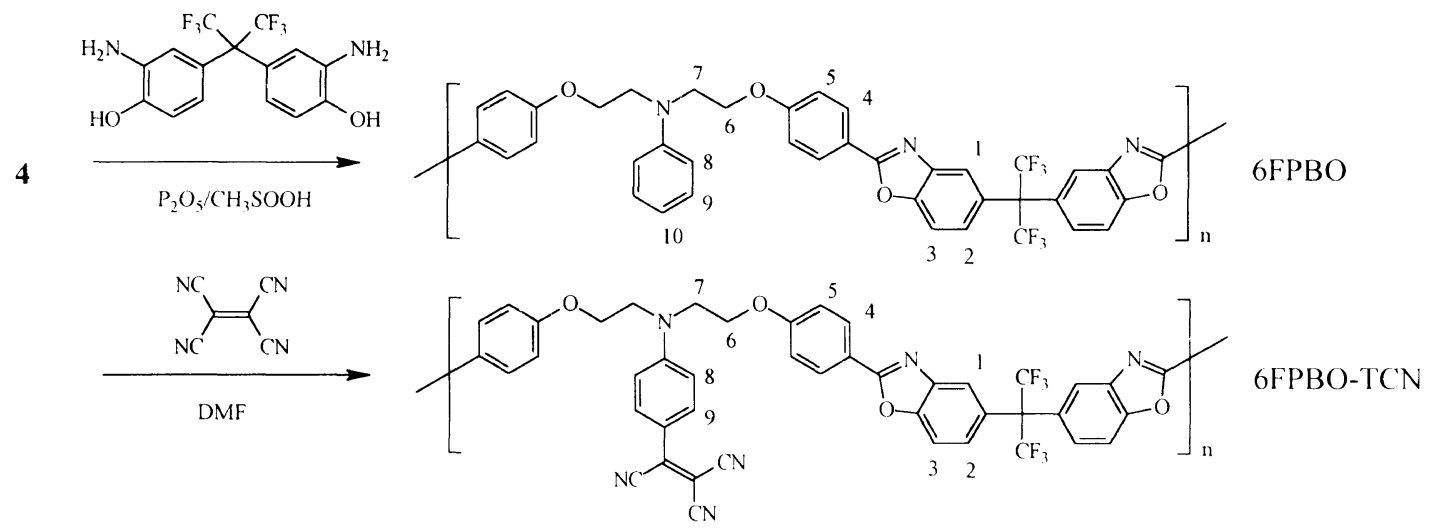

Figure 2. Synthesis of NLO active polybenzoxazole.

\section{Synthesis of Diacid Monomer}

In a $500 \mathrm{~mL}$ flask, 4-fluorobenzonitrile $(24.2 \mathrm{~g}, 20$ $\mathrm{mmol})$ and $N$-phenyldiethanolamine $(9.06 \mathrm{~g}, 50 \mathrm{mmol})$ were dissolved in $100 \mathrm{~mL}$ of $N, N$-dimethylformamide (DMF). Potassium carbonate $(13.8 \mathrm{~g}, 0.1 \mathrm{~mol})$ was added into the solution, and stirred for $24 \mathrm{~h}$ at $100^{\circ} \mathrm{C}$, and then the mixture was poured into water. The white precipitate was collected by filtration, and recrystallized from methanol to give white crystals of dicyano compound; $\mathrm{mp} 97-98^{\circ} \mathrm{C}$. The yield was $19.2 \mathrm{~g}(65 \%)$. The infrared (IR) spectrum (KBr) exhibited absorption at $2220 \mathrm{~cm}^{-1}$ $(\mathrm{CN})$. The ${ }^{1} \mathrm{H}$ nuclear magnetic resonance (NMR) spectrum [dimethyl sulfoxide (DMSO)- $d_{6}$ ] showed peaks at $\delta 3.83\left(\mathrm{t}, 4 \mathrm{H}, \mathrm{NCH}_{2}\right), 4.20\left(\mathrm{t}, 4 \mathrm{H}, \mathrm{OCH}_{2}\right), 6.61(\mathrm{t}, 1 \mathrm{H}$, ArH), 6.80 (d, 2H, ArH), 7.08 (d, 4H, ArH), 7.14 (t, 2H, $\mathrm{ArH})$, and $7.70 \mathrm{ppm}(\mathrm{d}, 4 \mathrm{H}, \mathrm{ArH})$.

The portion of $10.0 \mathrm{~g}(26 \mathrm{mmol})$ of dicyano compound was dissolved in a mixed solution of $25 \mathrm{~g}$ of sodium hydroxide, $150 \mathrm{~mL}$ of methanol, and $450 \mathrm{~mL}$ of water. The solution was heated at reflux with stirring for 3 days. The solution was cooled, and the $\mathrm{pH}$ value was adjusted by diluted hydrochloric acid to about $3-4$. The white precipitate was collected by filtration and washed with water, and dried under vacuum; $\mathrm{mp} 233-235^{\circ} \mathrm{C}$. Yield: $10.8 \mathrm{~g}(99 \%)$. IR (KBr): $1681 \mathrm{~cm}^{-1}(\mathrm{C}=\mathrm{O}) .{ }^{1} \mathrm{H}$ NMR $\left(\mathrm{DMSO}-d_{6}\right): \delta 3.83\left(\mathrm{t}, 4 \mathrm{H}, \mathrm{NCH}_{2}\right), 4.20\left(\mathrm{t}, 4 \mathrm{H}, \mathrm{OCH}_{2}\right)$, $6.61(\mathrm{t}, 1 \mathrm{H}, \mathrm{ArH}), 6.80$ (d, 2H, ArH), 6.96 (d, 4H, ArH), $7.14(\mathrm{t}, 2 \mathrm{H}, \mathrm{ArH}), 7.82(\mathrm{~d}, 4 \mathrm{H}, \mathrm{ArH})$, and $12.6 \mathrm{ppm}(\mathrm{s}$, $2 \mathrm{H}, \mathrm{COOH}$ ). Anal. calcd for $\mathrm{C}_{24} \mathrm{H}_{23} \mathrm{NO}_{6}$ (421.4): $\mathrm{C}$, $68.4 \%$; H, 5.50\%; N, 3.32\%. Found: C, 68.3\%; H, $5.52 \% ; \mathrm{N}, 3.34 \%$.

\section{Synthesis of Polybenzoxazole (6FPBO)}

In a $50 \mathrm{~mL}$ flask fitted with mechanical stirrer, diacid $(1 \mathrm{~g}, 2.37 \mathrm{mmol})$ was dissolved in $12 \mathrm{~mL}$ of PPMA, and 6 FAP $(0.869 \mathrm{~g}, 2.37 \mathrm{mmol})$ was added to this solution at room temperature. The mixture was stirred for $5 \mathrm{~h}$ at $140^{\circ} \mathrm{C}$ under nitrogen. After cooling, the polymer so- lution was poured into an aqueous alkaline solution, and the precipitated polymer was collected and heated at reflux in methanol for $2 \mathrm{~h}$. The polymer powder was collected by filtration, and washed thoroughly with water, and dried under vacuum. Yield: $1.57 \mathrm{~g} \mathrm{(84 \% )}$. The inherent viscosity measured in 1-methyl-2-pyrrolidinone (NMP) at a concentration of $0.5 \mathrm{~g} \mathrm{dL}^{-1}$ at $30^{\circ} \mathrm{C}$, was $0.26 \mathrm{dL} \mathrm{g}^{-1}$. IR $(\mathrm{KBr}): 1602(\mathrm{C}=\mathrm{N}, \mathrm{C}=\mathrm{C}), 1251$ $(\mathrm{C}-\mathrm{O}-\mathrm{C}) \mathrm{cm}^{-1} .{ }^{1} \mathrm{H}$ NMR [tetrahydrofuran (THF)- $d_{8}$ ]: $\delta 4.09\left(4 \mathrm{H}, \mathrm{NCH}_{2}\right), 4.43\left(4 \mathrm{H}, \mathrm{OCH}_{2}\right)$, and $6.79-8.30$ ppm (19H, ArH).

\section{Tricyanovinylation of Polybenzoxazole (6FPBO-TCN)}

The $1.0 \mathrm{~g}$ of polybenzoxazole was dissolved in $10 \mathrm{~mL}$ of DMF at room temperature under nitrogen. Tetracyanoethylene $(0.197 \mathrm{~g}, 1.54 \mathrm{mmol})$ was added into this solution. This solution was reacted with stirring for $12 \mathrm{~h}$ at $80^{\circ} \mathrm{C}$. Then, the solution was poured into water to precipitate, and the red polymer powder was filtered, washed with water, and dried under vacuum. Yield: $1.05 \mathrm{~g}(92 \%)$. The inherent viscosity at a concentration of $0.5 \mathrm{~g} \mathrm{dL}^{-1}$ at $30^{\circ} \mathrm{C}$ in NMP, was $0.27 \mathrm{dL} \mathrm{g}^{-1}$. IR spectrum (KBr): $2217(\mathrm{CN}), 1603(\mathrm{C}=\mathrm{N}, \mathrm{C}=\mathrm{C}), 1250$ $(\mathrm{C}-\mathrm{O}-\mathrm{C}) \mathrm{cm}^{-1} .{ }^{1} \mathrm{H}$ NMR $\left(\mathrm{THF}-d_{8}\right): \delta 4.14-4.53(8 \mathrm{H}$, $\left.\mathrm{OCH}_{2} \mathrm{CH}_{2} \mathrm{~N}\right)$, and $7.10-8.31 \mathrm{ppm}(18 \mathrm{H}, \mathrm{ArH})$.

\section{RESULTS AND DISCUSSION}

\section{Synthesis of Diacid Monomer and Polybenzoxazole}

Synthesis of $N$-phenylated diacid monomer was shown in Figure 2. Diacid compound was easily synthesized in high yield by a condensation of $N$-phenyldiethanolamine with 4-fluorobenzonitrile, followed by alkaline hydrolysis.

The fluorine containing bisaminophenol monomer, 6FAP was introduced to enhance the solubility of polybenzoxazole. The 6 FPBO was synthesized by onestep thermal polycondensation of diacid 4 with 6FAP 


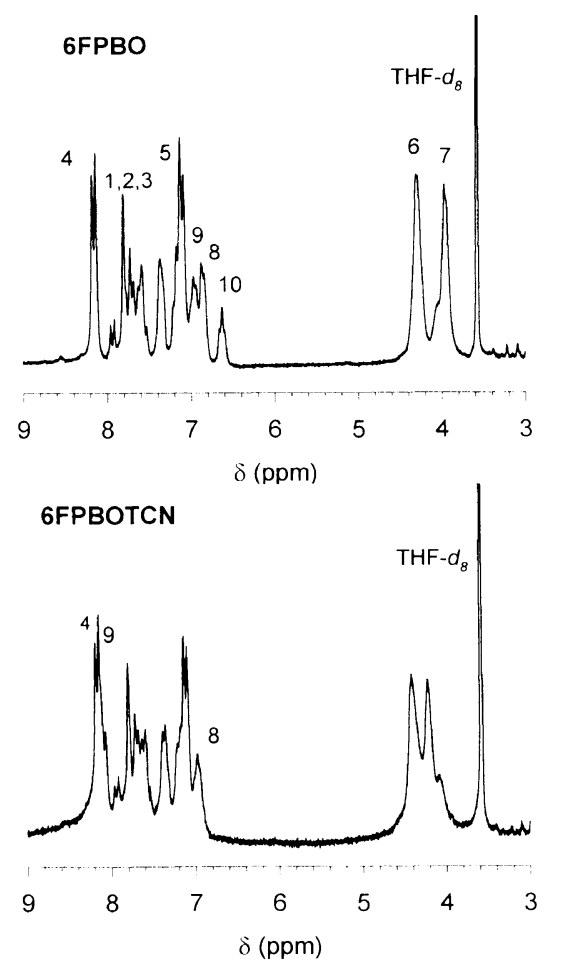

Figure 3. ${ }^{1} \mathrm{H}$ NMR spectra of polybenzoxazole before (6FPBO) and after tricyanovinylation (6FPBO-TCN).

using the procedure reported by Ueda et al. ${ }^{12}$ Typically, PPMA was used as a dehydrating agent and polymerization medium at $140^{\circ} \mathrm{C}$. Polybenzoxazole with moderate inherent viscosity of $0.27 \mathrm{dL} \mathrm{g}^{-1}$ was successfully obtained. As a NLO chromophore, $N, N$-disubstituted-4-tricyanovinylaniline was introduced by posttricyanovinylation of $N$-phenyl pendants of 6 FPBO. The tricyanovinylation method has been well established by ROI Technology researchers and others. ${ }^{13-15}$ The post tricyanovinylation of 6FPBO was generally carried out by reacting $6 \mathrm{FPBO}$ with tetracyanoethylene (1.1 equiv.) in DMF at $80^{\circ} \mathrm{C}$ for $12 \mathrm{~h}$.

The degree of substitution of tricyanovinyl group in $N$-phenyl pendant was quantitative, which was determined by ${ }^{1} \mathrm{H}$ NMR spectroscopy. After tricyanovinylation, the peak of proton at para-position $(6.8 \mathrm{ppm})$ in $N$-phenyl was completely disappeared and those at ortho- and meta-position (7.0 and $7.1 \mathrm{ppm})$ in $N$-phenyl were shifted to 7.1 and $8.2 \mathrm{ppm}$ because of strong electron-affinity of tricyanovinyl group as shown in Figure 3.

\section{General and Nonlinear Optical Properties of Polybenz- oxazole}

The thermal properties of polybenzoxazole were summarized in Table I. The precursor polymer, 6FPBO had a little low glass transition temperature of about $144^{\circ} \mathrm{C}$ due to the flexible aliphatic main chain. The glass transition temperature $\left(T_{\mathrm{g}}\right)$ of polybenzoxazole $(6 \mathrm{FPBO}-$ TCN) after tricyanovinylation increased up to $180^{\circ} \mathrm{C}$, ascribing to the introduction of extended rigid tricyanovinyl unit. Moreover, the thermal stability determined by TG was remarkably enhanced as shown in Figure 4. The initial decomposition temperature of 6FPBO-TCN was about $300^{\circ} \mathrm{C}$, meaning that polybenzoxazole might
Table I. Properties of polybenzoxazoles

\begin{tabular}{|c|c|c|c|c|c|}
\hline & $\eta_{\mathrm{inh}}{ }^{\mathrm{a}}$ & $T_{\mathrm{g}}^{\mathrm{b}}$ & $T_{\mathrm{d}}^{\mathrm{c}}$ & $\lambda_{\max } \mathrm{c}$ & $r_{33}{ }^{\mathrm{e}}$ \\
\hline & $\mathrm{dL} \mathrm{g}^{-1}$ & ${ }^{\circ} \mathrm{C}$ & ${ }^{\circ} \mathrm{C}$ & $\mathrm{nm}$ & $\mathrm{pm} \mathrm{V}^{-1}$ \\
\hline $6 \mathrm{FPBO}$ & 0.26 & 144 & 300 & - & - \\
\hline 6FPBO-TCN & 0.27 & 180 & 340 & 510 & 34 \\
\hline
\end{tabular}

${ }^{a}$ Determined at a concentration of $0.5 \mathrm{~g} \mathrm{dL}^{-1}$ at $30^{\circ} \mathrm{C}$ in NMP. ${ }^{\mathrm{b}}$ Glass transition temperatures measured by DSC at a heating rate of $20^{\circ} \mathrm{C} \mathrm{min}^{-1}$. ${ }^{\mathrm{c}}$ Initial decomposition temperaturés measured by TG at a heating rate of $10^{\circ} \mathrm{C} \mathrm{min}^{-1}$ under nitrogen. ${ }^{\mathrm{d}}$ Maximum absorption in film. ${ }^{\mathrm{e}}$ At a wavelength of $633 \mathrm{~nm}$.

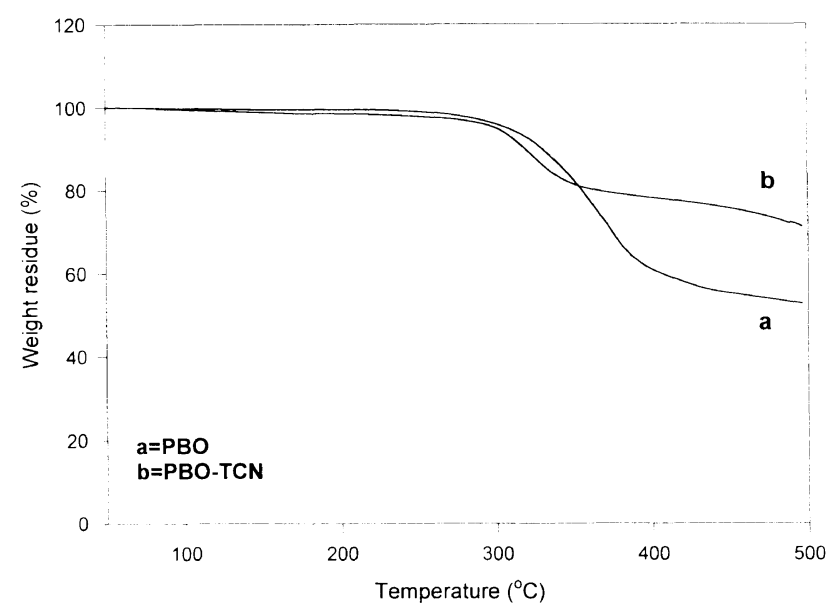

Figure 4. TG curves of $6 \mathrm{FPBO}$ and $6 \mathrm{FPBO}-\mathrm{TCN}$.

be one of the promising NLO materials with excellent thermal stability. Polybenzoxazole film with tricyanovinylaniline chromophores had a UV maximum absorption $\left(\lambda_{\max }\right)$ of $510 \mathrm{~nm}$.

The 6FPBO-TCN was soluble in organic solvents such as tetrahydrofuran, pyridine, cyclohexanone and 1,1,2,2tetrachloroethane, therefore could be spin-casted onto an indium tinoxide (ITO) coated substrate to give an optically transparent polymer film.

For the dipole alignment of chromophores we tried contact poling by applying electric field to sandwitch type sample. Gold was evaporated as a top electrode on the thin film of 6FPBO-TCN casted onto ITO substrate as a bottom electrode. The polybenzoxazole film showed high breakdown voltage, therefore could be processed even at higher poling field. At a poling field of $1.5 \mathrm{MV}$ $\mathrm{cm}^{-1}$, the electro-optic coefficient, $r_{33}$ was $34 \mathrm{pm} \mathrm{V}^{-1}$ at a wavelength of $633 \mathrm{~nm}$ measured by simple reflection method. The temporal stability of $r_{33}$ was measured at $100^{\circ} \mathrm{C}$, which is simply evaluated by the curve of $r_{33}(t) / r_{33}(0) v s$. time, as shown in Figure 5. The $r_{33}$ value of $6 \mathrm{FPBO}-\mathrm{TCN}$ after 1 week at $100^{\circ} \mathrm{C}$ was maintained to $90 \%$ of initial $r_{33}$ value, that was similar trend to general polyimide system. ${ }^{14}$

The dipole alignment behavior in polybenzoxazole and polyimide system can be compared through the UV-Vis absorbance spectra before and after poling. For this, we synthesized a corresponding polyimide (6FPI-TCN) with tricyanovinyl chromophore (Figure 6). The detail synthesis of 6FPI-TCN will be reported elsewhere. Figure 7 shows the UV-Vis spectra of 6FPBO-TCN and 6FPI$\mathrm{TCN}$, before and after poling, respectively. The order 


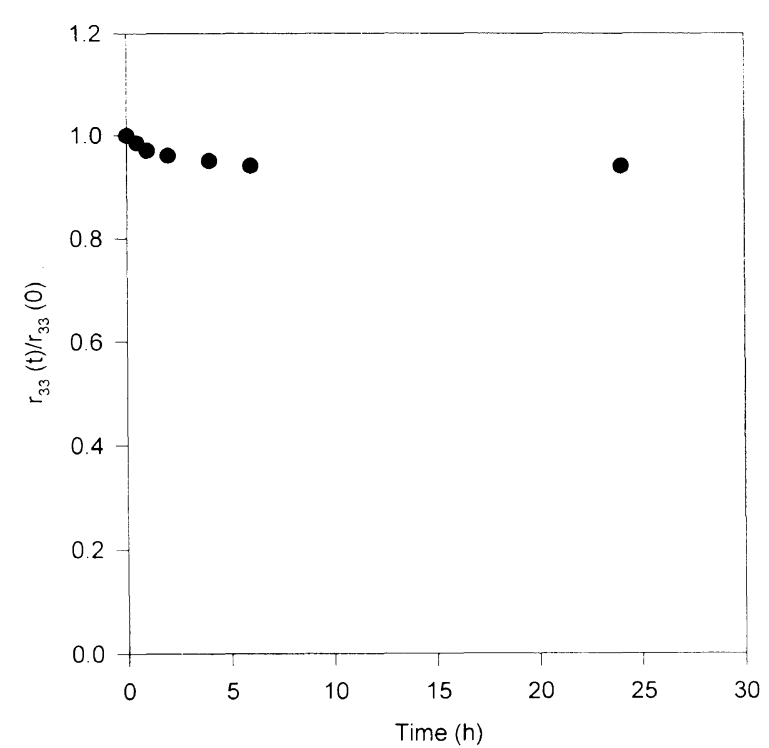

Figure 5. Temporal stability of electro-optic coefficient of 6FPBOTCN.

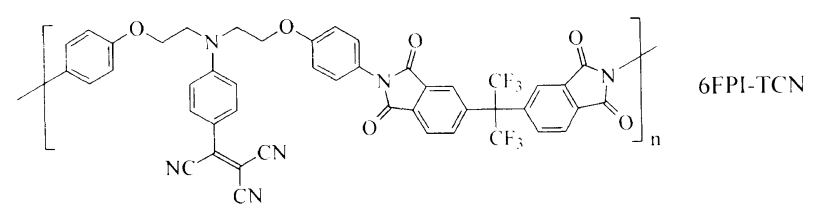

Figure 6. The structure of polyimide (6FPI-TCN).

6FPBO-TCN

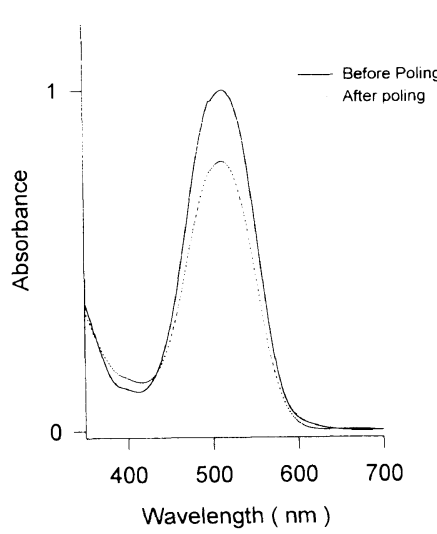

Figure 7. UV-Vis spectra of unpoled 6FPBO-TCN and poled 6 FPBO-TCN; and unpoled 6FPI-TCN and poled 6 FPI-TCN, respectively.

parameter, $\left(\Phi=1-A_{\mathrm{p}} / A_{0}\right)$ was obtained by measuring the maximum absorbance of unpoled film $\left(A_{0}\right)$ and poled film $\left(A_{\mathrm{p}}\right)$ by UV spectroscopy. It was found that poling efficiency of polybenzoxazole was a little different from that of polyimide when poled at each $T_{\mathrm{g}}$. Poled polybenzoxazole films had always lower order parameter values $(0.17-0.22)$ than poled polyimide films $(0.30$ 0.35 ) at similar poling conditions (film thickness, voltage, and time), implying more difficulty of dipole alignment in polybenzoxazole system. It was perhaps attributed to better chain packing of polybenzoxazole due to nonexistence of carbonyl groups, resulting smaller free volume to move chromophores.

\section{CONCLUSIONS}

As a new type of thermally stable NLO polymeric system, polybenzoxazoles were synthesized by direct polycondensation of diacid containing $N$-phenyl pendant with bisaminophenol using PPMA, followed by post-substitution of tricyanovinyl group. This NLO polybenzoxazole had a high glass transition temperature of about $180^{\circ} \mathrm{C}$ and an initial decomposition temperature of about $300^{\circ} \mathrm{C}$, meaning excellent thermal stability comparable to polyimide system. Electro-optic coefficient of polybenzoxazole film poled at $1.5 \mathrm{MV} \mathrm{cm}^{-1}$ was measured to $34 \mathrm{pm} \mathrm{V}^{-1}$ (at $633 \mathrm{~nm}$ ) and showed its long term stability.

\section{REFERENCES}

1. (a) D. Chemla and J. Zyss, Ed., "Nonlinear Optical Properties of Organic Materials and Crystals," Academic, Orlando, FL, 1987. (b) P. Prasad and D. Williams, Ed., "Nonlinear Optical Effects in Molecules and Polymers," John Wiley and Sons, New York, N.Y., 1991.

2. D. M. Burland, R. D. Miller, and C. A. Walsh, Chem. Rev., 94, 31 (1994).

3. S. Jacobson, P. Landi, T. Findakly, J. Stamatoff, and H. Yoon, J. Appl. Polym. Sci., 53, 649 (1994).

4. Z. Peng and L. Yu, Macromolecules, 27, 2638 (1994).

5. D. Yu, A. Gharavi, and L. Yu, Macromolecules, 28, 784 (1995).

6. T. Verbiest, D. M. Burland, M. C. Jurich, V. Y. Lee, R. D. Miller, and W. Volksen, Science, 268, 1604 (1995).

7. D. Yu and L. Yu, Macromolecules, 27, 6718 (1994).

8. D. Yu, A. Gharavi, and L. Yu, J. Am. Chem. Soc., 117, 11680 (1995).

9. K. H. Park, W. S. Jahng, S. J. Lim, and N. Kim, Mol. Cryst. Liq. Cryst., 280, 27 (1996).

10. W. W. Moyer, Jr., C. Cole, and T. Anyos, J. Polym. Sci., Part A, 3, 2107 (1965).

11. D. H. Choi, S. Song, T. S. Lee, S. Y. Park, and N. Kim, J. Appl. Polym. Sci., 59, 9 (1996).

12. M. Ueda, H. Sugita, and M. Sato, J. Polym. Sci., Part A, Polym. Chem. Ed., 24, 1019 (1986).

13. A. K.-Y. Jen, V. P. Rao, K. J. Drost, Y. Cai, R. M. Mininni, J. T. Kenny, E. S. Binkley, and L. R. Dalton, Proc. SPIE, 2285 , 49 (1994).

14. K. J. Drost, A. K.-Y. Jen, and V. P. Rao, Chemtech., Sept., 16 (1995).

15. T.-A. Chen, A. K.-Y. Jen, and Y. Cai, Chem. Mater., 8, 607 (1996). 